\title{
A Study on Antimicrobial Evaluation of Newly Synthesized Antipyrin Analogues
}

\author{
Sahoo Jyotirmaya ${ }^{1 *}$, Paidesetty Sudhir Kumar ${ }^{2}$ \\ ${ }^{1}$ Department of Pharmaceutics, Sri Jayadev College of Pharmaceutical Sciences, Bhubaneswar 752101, Odisha, INDIA. \\ ${ }^{2}$ Department of Pharmaceutical Chemistry, School of Pharmaceutical Sciences, Siksha 'O' Anusandhan University, \\ Bhubaneswar 751003, Odisha, INDIA.
}

\begin{abstract}
The antipyrinyl derived molecules are a versatile building blocker organic compounds and used in medicinal drug research. A versatile range of hybrid molecules have been synthesized by diazotization of 4-aminoantipyrin and further substituted with six different coupling components. The structures of the synthesized compounds have been confirmed by different spectral techniques. The antimicrobial activity of the synthesized molecules is investigated by agar well diffusion method against a wide range of microbial strains. The results of the antimicrobial activities of the novel synthesized molecules are statistically interpreted by dunnet post hoc test. It is found to be observed that the compound 4-[(4-Hydroxy-2-oxo-2H-chromen-3-yl)diazenyl]-1, 5-dimethyl-2-phenyl$1 \mathrm{H}$-pyrazol-3(2H)-one (4a) showed significant antimicrobial activity against $S$. flexneri, K. pneumonia, M. luteus, S. mitis, B. subtilis and $S$. aureus in comparison to standard ampicillin. The solvatochromic study of the synthesized compounds revealed that the compound 4-((2, 4-dihydroxyphenyl) diazenyl)-1, 5-dimethyl-2-phenyl-1H-pyrazol-3(2H)-one (4d) 4-((2-hydroxynaphthalen-1-yl) diazenyl)-1, 5-dimethyl-2-phenyl-1H-pyrazol-3(2H)-one (4e) showed good bathochromic shift in comparison to other solvents used. These novel synthesized azo molecules may be suggested for new establishment chemical class of antimicrobial agents and to create an opportunity in new drug discovery and medicinal research.
\end{abstract}

Key words: Diazotization, Antimicrobial, Acute Toxicity, Solvatochromic.

\section{INTRODUCTION}

Frequently indiscriminate using of antibiotics is not only abusing the rational use of drugs but also develop antibiotic resistance within the pathogenic micro-organisms. Multi drug resistance in various pathogenic organisms also develop resistance genes within their DNA which further transfer to other sensitive organisms during their mutation. Inclusion of emerging infectious diseases like severe acute respiratory syndrome and avian influenza is a worldwide problem. Therefore it needs continues development of novel antimicrobials to overcome such problems. 4-aminoantipyrin nucleus is the key pharmacophore and has been reported with various pharmacological activities such as analgesic, ${ }^{1}$ antimicrobial, ${ }^{2}$ antidepressant ${ }^{3}$ and antitumor agents. ${ }^{4} 4$-Hydroxycoumarin derived molecules possess a versatile biological activities viz: anticoagulant, ${ }^{5}$ anti-viral, ${ }^{6}$ anticancer ${ }^{7}$ etc. activities. 8-Hydroxyquinoline, an organic compound that consists of a phenol ring fused to a pyridine ring popular for their various pharmacological actions, ${ }^{8}$ The structure of salicylic acid nucleus is deduced as 2-hydroxy benzoic acid. The molecules bearing salicylic acid nucleus possess antioxidant, antiproliferative ${ }^{9}$ and cytotoxic ${ }^{10}$ activities. The 1,3-benzenediol derivatives are good phenolic candidates with expecting clinical activity. ${ }^{11}$ The compounds of naphthalene derivatives in various literatures reported with different biological activities like antimicrobial activities and HIV-1
Submission Date: 16-03-2017; Revision Date: 25-04-2017; Accepted Date: 05-07-2017

DOI: 10.5530/ijper.51.4.108 Correspondence: Sahoo Jyotirmaya, Assistant Professor Department of Pharmaceutics, Sri Jayadev College of Pharmaceutical Sciences, Bhubaneswar 752101,

Odisha, INDIA.

Phone no: +91 9861433157; E-mail: jjyotisahoo@rediffmail.com

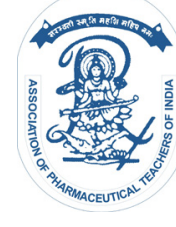

www.ijper.org 
integrase inhibitory effect. ${ }^{12}$ Azo molecules are well accepted for their medicinal uses such as antibacterial, ${ }^{13}$ antitumor, ${ }^{14}$ antiseptics ${ }^{15}$ and antioxidant ${ }^{13}$ properties. All these above information trumpeted to develop such hybrid molecules in which both 4-aminoantipyrin nucleus and azo group can be kept together. Thus it is decided to couple different nucleophiles with 4-aminoantipyrin nucleus by azo coupling reaction and to evaluate their antimicrobial property.

\section{MATERIALS AND METHODS EXPERIMENTAL SECTION}

\section{Chemicals and Analysis}

For the present research purpose the chemicals used are of synthetic grade, sourced from Merck Ltd. and Hi Media Laboratories Pvt. Ltd., Mumbai, India. Melting points are found to be uncorrected and were determined on Elico Melting point apparatus. The synthesized molecules are analyzed by FT/IR (JASCO FT/IR 4100 Spectrophotometer using $\mathrm{KBr}$ disc). The ${ }^{1} \mathrm{H}$ NMR spectra were recorded on a (Bruker ${ }^{1} \mathrm{H}$ NMR $300 \mathrm{MH} \approx$ ) using Tetramethyl silane as an internal standard and the chemical shifts were expressed on $\delta$ ppm. UV (JASCO V-630 Spectrophotometer) and LC-MS (Shimadzu-Mass spectrometer) were used for observation of solvent effects and molecular mass respectively. Elemental Analysis for C, H, N and S were performed on Perkin Elmer model 2400 CHNS/O analyzer.

\section{General procedure for the synthesis of antipyrinyl azo analogues $4(a-f)^{16}$}

The novel antipyrinyl azo molecules are synthesized by the method mentioned with little modification. A cold solution of $2.5 \mathrm{~mL}$ of sodium nitrite $(0.206 \mathrm{~g}, 3 \mathrm{mmol})$ was added drop wise to ice-cold solution of 4-aminoantipyrin in conc. $\mathrm{HCl}$ and water in equal proportion. The temperature of the reaction was maintained up to $0-5^{\circ} \mathrm{C}$. When addition was completed, the solution was kept about 5 min with occasional stirring to complete the diazotization. Then it was poured into an ice cold solution of six different neutral nucleophiles in presence of sodium acetate buffer (Scheme). The mixture was allowed to stand on an ice bath for 10-15 min. The reaction mixture was adjusted at a $\mathrm{pH}$ range of 5-6. Thus the obtained coloured products were filtered, washed with water and dried. Finally obtained products (4a-4f) were re-crystallized from ethanol and dried.

4-[(4-Hydroxy-2-oxo-2H-chromen-3-yl)diazenyl]-1, 5-dimethyl2-phenyl-1H-pyrazol-3(2H)-one (4a): Cherry red colour; Yield $75 \%$; $\mathrm{R}_{\mathrm{p}}$; 0.6, $\mathrm{mp}\left({ }^{\circ} \mathrm{C}\right)$; 180-190; UV-vis $(\lambda \max$, $\mathrm{nm}$, methanol): 389; IR (KBr, $\left.\gamma, \mathrm{cm}^{-1}\right): 3495$ (O-H str),
2925 (Ar-CH3),1716 (C-O str. lactone carbonyl), 1664 (C=O str. Pyrazolone), 1607 ( $\mathrm{C}=\mathrm{C}$ str), $1557(\mathrm{~N}=\mathrm{N})$, 1483 ( C-N str.), 1282 (C=O str.), 1132 (O-H bending); ${ }^{1} \mathrm{H} \mathrm{NMR}\left(\mathrm{CDCl}_{3}, \delta \mathrm{ppm}, 300 \mathrm{MHz}\right.$ ): 8.08 (d, coumarin $\mathrm{H}-5$,), 7.41(m, coumarin H-6), 7.64 (m, coumarin $\mathrm{H}-7), 7.43$ (d, coumarin H-8), 7.64-7.99 (m, 5H, ArH), $3.19\left(3.19\left(\mathrm{~s}, 3 \mathrm{H}, \mathrm{N}-\mathrm{CH}_{3}\right), 2.65\right.$ (s, 3H, C-CH $\left.{ }_{3}\right), 13.56$ (s, $1 \mathrm{H}, 4-\mathrm{OH}$ ); Analysis Calcd $\%$ for $\mathrm{C}_{20} \mathrm{H}_{16} \mathrm{~N}_{4} \mathrm{O}_{4}$ : C, 63.82; H,4.28; N, 14.89, Found \%: C 63.75; H 4.25; N 14.95, $m / z ; 377.18$ (90.15\%), 274.02 (14.9\%).

4-((8-hydroxyquinolin-5-yl) diazenyl)-1, 5-dimetbyl-2-phenyl1H-pyrazol-3(2H)-one (4b): Gray colour; Yield $90 \%$; $\mathrm{R}_{\mathrm{f}}$; 0.7, $\mathrm{mp}\left({ }^{\circ} \mathrm{C}\right) ; 261-265$; UV-vis $\left(\lambda_{\text {max }}, \mathrm{nm}\right.$, methanol): 397; IR $\left(\mathrm{KBr}, \gamma, \mathrm{cm}^{-1}\right): 3370$ (O-H str), $2923\left(\mathrm{CH}_{2}\right.$ str. Methyl), 1674 (C=O str. Pyrazolone), 1581 (C=Nstr. Quinolinyl), 1541 (-N=N-), 1274 (C-Ostr.); ${ }^{1} \mathrm{H}$ NMR (DMSO-d6, $\delta$ ppm, $300 \mathrm{MHz}$ ): 2.74 (s, 3H, =C-CH ), 3.39 (s, 3H, $\mathrm{N}-\mathrm{CH}_{3}$ ), 7.17-7.43 (m, 5H, Aryl-H), 9.33 (dd, Quinolinyl H-2), 7.53 (dd, Quinolinyl H-3), 8.77 (d, Quinolinyl H-4), 8.10 (d, Quinolinyl H-6), 8.17 (d, Quinolinyl H-7); LC-MS (\% area) 78.11; $\mathrm{m} / z ; 360.24(\mathrm{M}+1)$; Analysis for $\mathrm{C}_{20} \mathrm{H}_{17} \mathrm{~N}_{5} \mathrm{O}_{2}$ : Calcd \% C, 66.84; H, 4.77; N, 19.49; Found $\%$ : C, 66.81; H, 4.75; N, 19.51 .

5-((1,5-dimetbyl-3-oxo-2-phenyl-2,3-dibydro-1H-pyrazol-4-yl) azo)-2- bydroxybenzoic acid (4c): Brown colour powder, yield $85 \%$; $\mathrm{R}_{\mathrm{f}} 0.7 ; \mathrm{mp}\left({ }^{\circ} \mathrm{C}\right) ; 256-260$, UV-vis $\left(\lambda_{\max }\right.$, ethanol): $368 \mathrm{~nm}$; IR $\left(\mathrm{KBr}, \gamma, \mathrm{cm}^{-1}\right): 3410$ (O-H str.), 2926 (CH str.), 1662 (C=O str. of Pyrazolone group), 1606 (C=C str.), 1486(-N=N-), 1153 (C-O str); ${ }^{1} \mathrm{H}$ NMR (DMSO, 8ppm, 300MHz): 6.85- $7.30\left(\mathrm{~m}, 5 \mathrm{H},-\mathrm{N}_{-} \mathrm{C}_{6} \mathrm{H}_{5}\right.$ ), $2.60\left(\mathrm{~s}, 3 \mathrm{H},=\mathrm{C}-\mathrm{CH}_{3}\right), 3.15\left(\mathrm{~s}, 3 \mathrm{H},-\mathrm{N}-\mathrm{CH}_{3}\right), 11.65$ (sb. $1 \mathrm{H}, \mathrm{OH}), 12.17(\mathrm{sb}, 1 \mathrm{H}, \mathrm{COOH}), 7.32$ (d, 1H, salicylic $\mathrm{H}-3), 7.41$ (d, 1H, salicylic H-4), 7.87 (s, 1H, salicylic H-6); LC-MS ( $\%$ area); 39.20; $\mathrm{m} / \% 353.07(\mathrm{M}+1)$; Analysis for $\mathrm{C}_{18} \mathrm{H}_{16} \mathrm{~N}_{4} \mathrm{O}_{4}$ : Calcd \% C, 61.36; $\mathrm{H}, 4.58 ; \mathrm{N}$, 15.90; Found \% C, 61.46; H, 4.38; N, 15.87.

4-((2, 4-dibydroxyphenyl) diazenyl)-1, 5-dimetbyl-2-phenyl1H-pyrazol-3(2H)-one (4d): Gray colour powder, Yield $70 \%, \mathrm{R}_{\mathrm{f}}$ 0.7; $\mathrm{mp}\left({ }^{\circ} \mathrm{C}\right) ; 217-220$; UV-vis $\left(\lambda_{\max }\right.$, ethanol):420 nm; IR (KBr, $\gamma$, cm$\left.^{-1}\right): 3173$ (O-Hstr.), 1604 ( $\mathrm{C}=\mathrm{C}$ str. resorcinol) 1687 (C=O str. pyrazolone), 1493 (-N=N-), 1258 (O-H bend), 1050 (C-O str.),1024 (C-N str.); ${ }^{1} \mathrm{H}$ NMR (DMSO-d6, $\delta$ ppm, $300 \mathrm{MHz}$ ): 10.14 (s, 1H, OH), 3.39 (s, 3H, N-CH $), 2.49$ (s, 3H, $\left.=\mathrm{C}-\mathrm{CH}_{3}\right), 6.43(\mathrm{~s}, 1 \mathrm{H}$, resorcinol $\mathrm{H}-2), 7.37(\mathrm{~d}, 1 \mathrm{H}$, resorcinol H-5, ), 6.40 (d, $1 \mathrm{H}$, resorcinol H-6), 7.41-7.59 (m, 5H, ArH); LC-MS (ret. time, \% area); 1.740, 51.83; $m / z ; 325.2(\mathrm{M}+1)$; Analysis for $\mathrm{C}_{17} \mathrm{H}_{16} \mathrm{~N}_{4} \mathrm{O}_{3}$ : Calcd \% C, 62.95; H, 4.97; N, 17.27; Found \%: C, 62.97; H, 4.95; $\mathrm{N}, 17.25$.

4-((2-bydroxynaphthalen-1-yl) diazenyl)-1, 5-dimetbyl-2-phenyl1H-pyrazol-3(2H)-one (4e): Brick red colour powder; 
Yield $90 \%$; $\mathrm{R}_{\mathrm{f}}$ 0.7; m.p.: $170-80{ }^{\circ} \mathrm{C}$; UV-vis $\left(\lambda_{\max }\right.$, ethanol):448 nm; IR (KBr, $\left.\gamma, \mathrm{cm}^{-1}\right): 3439,3235$ (O-H str.), $2924\left(\mathrm{CH}_{2}\right.$ str. of $\left.\mathrm{CH}_{3}\right), 1661$ ( $\mathrm{C}=\mathrm{O}$ str. of pyrazolone), 1582, 1515 (C=C str.), 1461 (-N=N-), 1395 (O-H bend.), 1243 (C-Ostr.); ${ }^{1} \mathrm{H}$ NMR (DMSO-d ${ }_{6}, \delta$ ppm, 300 MHz): 12.71 (s, 1H, OH), 8.76 (1H, naphthyl H-8), 8.74 (1H, naphthyl H-5), 7.76(1H, naphthyl H-4), $7.53(1 \mathrm{H}$, naphthyl H-7), 7.49 (1H, naphthyl $\mathrm{H}-6), 7.14(1 \mathrm{H}$, naphthyl H-3), 7.09-7.37 (m, 5H, ArH), 3.35 (s, 3H, N-CH $)_{3}$, 2.71 (s, 3H, = C- $\mathrm{CH}_{3}$ ); LC-MS (RT, \% area); 2.306, 100; m/ ₹: $359.30(\mathrm{M}+1)$; Analysis for $\mathrm{C}_{21} \mathrm{H}_{18} \mathrm{~N}_{4} \mathrm{O}_{2}$ : Calcd: C, 70.36; H, 5.09; N, 15.64 Found: C, 70.38; H, 5.06; N, $15.63 \%$.

5-((1,5-dimethyl-3-oxo-2-phenyl-2,3-dibydro-1H-pyrazol-4-yl) diazenyl)-2-bydroxybenzaldebyde (4f): Buff yellow colour powder; yield 90\%; $\mathrm{R}_{\mathrm{f}} 0.8$; $\mathrm{mp}\left({ }^{\circ} \mathrm{C}\right) ; 180-190$, UV-vis ( $\lambda$ max, ethanol): $347 \mathrm{~nm}$; IR $\left(\mathrm{KBr}, \gamma, \mathrm{cm}^{-1}\right): 3341(\mathrm{O}-\mathrm{H}$ str.), 2920 (CH str. of aldehyde), 1675 (C=O str. of aldehyde), 1655 ( $\mathrm{C}=\mathrm{O}$ str. of pyrazolone), 1608 ( $\mathrm{C}=\mathrm{C}$ str.), 1485 (-N=N-), 1121 (C-O str.); ${ }^{1} \mathrm{H}$ NMR (DMSOd6, $\delta \mathrm{ppm}, 300 \mathrm{MHz}$ ): 11.37(s, 1H, OH), 10.23 (s, 1H, $\mathrm{CHO}), 2.46$ (s, 3H, C-CH $), 3.16$ (s, 3H, N-CH $), 7.01-$ 7.91 (m, 5H, Ar H), 8.19 (s, 1H, salicylaldehyde H-2), 7.59 (d,1H, salicylaldehyde H-5), 8.17 (d, 1H, salicylaldehyde H-6); LC-MS (\% area); 63; $m / z ; 336.11(\mathrm{M}+)$; Analysis for $\mathrm{C}_{18} \mathrm{H}_{16} \mathrm{~N}_{4} \mathrm{O}_{3}$ : Calcd \% C, 64.28; H, 4.79; N, 16.66; Found \%: C, 64.26; H, 4.81; N, 16.64 .

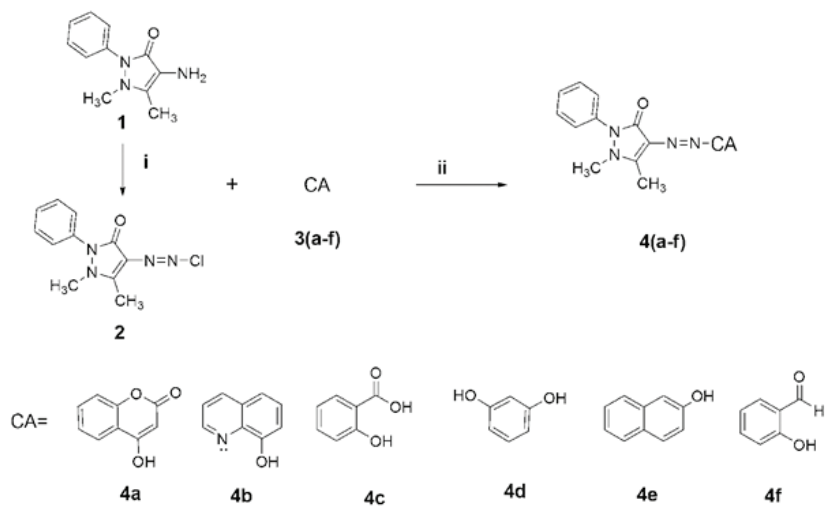

Reaction condition: - i. $\mathrm{NaNO}_{2} / \mathrm{HCl}, 0-5^{\circ} \mathrm{C}$, diazotization ii. acetate buffer, coupling reaction, $\mathrm{CA}=$ Coupling agents.

\section{Synthetic scheme of antipyrinyl azoanalogues (4a-4f)}

\section{Antimicrobial Evaluation}

The above novel synthesized antipyrinyl azo-molecules were investigated over different freshly sub cultured microbial strains Escherichia coli (MTCC 614), Salmonella enterica ser.typhi (MTCC 773), Salmonella enterica typhimurium (MTCC 98), Salmonella enterica paratyphi (MTCC 3220), Shigella flexneri (MTCC 1457), Pseudomonas aeruginosa
(MTCC 1035), Vibrio cholera (MTCC 3906), Klebsiella pneumoniae (MTCC 109), Micrococcus luteus (MTCC 1809), Bacillus circulans (MTCC 490), Streptococcus mitis (MTCC 2695) and Pectobacterium carotovorum (MTCC 1428) were procured from the Institute of Microbial Technology and Gene bank (IMTECH), Chandigarh, India. Staphylococcus aureus and Bacillus subtilis strains (freshly sub cultured) were obtained from University Department of Pharmaceutical Sciences, Utkal University. Ampicillin was used as reference antibiotics.

The antimicrobial diffusion test was performed using a cell suspension of about $1.5 \times 10^{6} \mathrm{CFU} \mathrm{mL} \mathrm{m}^{-1}$ employing a McFarland turbidity standard No. 0.5. The antimicrobial activity of the novel antipyrinylazo molecules (4a-4f) was performed by agar well diffusion method using sterile molten nutrient agar. ${ }^{17}$

\section{Minimum Inhibitory Concentration (MIC)}

To determine the minimum inhibitory concentration (MIC) a stock solution $\left(1 \mathrm{mgmL}^{-1}\right)$ of synthesized compounds was prepared using DMF. Further, different concentrations $\left(500,250,125,62.5\right.$ and $\left.31.25 \mu \mathrm{gmL}^{-1}\right)$ were prepared. Agar well diffusion method and serial dilution assay procedure was employed to determine minimum inhibitory concentration. The different concentrations for respective compounds were loaded into the wells and incubated at $37{ }^{\circ} \mathrm{C}$ for $18-24$ h. ${ }^{18,19}$

\section{Acute Toxicity Study}

The experiment was carried under the guideline of CPCSEA and approved by the IAEC. OECD guideline No.420 (2000) for the Acute Oral Toxicity- Fixed Dose Procedure of the test compounds (4a-4f) was followed.

\section{Statistical analysis}

The observed data on zone of inhibitions were subjected to one way analysis of variance. The mean zone of inhibition for each compound on each strain was compared with the reference antibiotic through Dunnett Post Hoc test https://www.statstodo.com/SSizAOV_Pgm.php). The test of significance was done at 5\% level of type one error. The research hypothesis was 'the zone of inhibition for test compound was higher than the reference antibiotic against the hypothesis of no difference (null hypothesis) which states that there is no significant difference between the zone of inhibition of the test compound and reference antibiotics.

\section{Sample size determination}

A minimum sample size of five was calculated taking probability of type 1 error $(d)=0.05$, Power $(1-\beta)=0.8$, Number of groups 13 within group $S D=2$. However a sample size of six has been taken in the study for each compound against each strain. 


\section{RESULTS AND DISCUSSION}

\section{Chemistry}

A series of six antipyrinyl azo-molecules (4a-4f) were synthesized by coupling of diazotized 4-amino antipyrin with different nucleophiles in presence of nitrosyl chloride on mild condition (Scheme). The excess of nitrous acid in the reaction was minimizing by addition of sodium acetate buffer. The nucleophiles are 4-hydroxy coumarin, 8-hydroxy quinoline, salicylic acid, 1,3-benzenediol, $\beta$-naphthol and salicylaldehyde. The purity of compounds was checked by TLC using silica gel with suitable solvents such as cyclohexane: ethyl acetate (60:40).

The elemental analysis of the synthesized antipyrinylazo molecules is found to have good agreement with their calculated values.

The FT/IR spectra of the synthesized molecules showed the vibration bands at a range of $\gamma 1655-1687 \mathrm{~cm}^{-1}$ assigned to $\mathrm{C}=\mathrm{O}$ str. of pyrazolone nucleus and the band for $-\mathrm{N}=\mathrm{N}$ - showed at a range of $\gamma 1461-1557 \mathrm{~cm}^{-1}$. The FT/IR spectral image of $\mathbf{4 a}$ is illustrated in Figure 1.

The ${ }^{1} \mathrm{H}$ NMR of the molecules suggested that the two sharp singlets appeared at a range of $\delta 2.46-2.79$ and 3.15-3.39 ppm attributed to the protons of methyl groups of 4-aminoantipyrin conjugated azo molecules. However the singlets appeared at $\delta 13.56,9.58,11.65$, $10.14,12.71$ and $11.37 \mathrm{ppm}$ corresponding the proton of $-\mathrm{OH}$ groups of the attached nucleophiles in the respective molecules $(\mathbf{4 a}-\mathbf{4} \mathbf{f})$ revealed their structural confirmation. The ${ }^{1} \mathrm{H}$ NMR spectral image of $4 \mathbf{c}$ is illustrated in Figure 2.

The solvent effect of the synthesized compounds is mentioned in Table 1. The solvatochromic effect of the synthesized compounds revealed that the molecule $4 \mathrm{~d}$ and $4 \mathrm{e}$ showed good bathochromic shift in most of the solvents may be due to the attachment of benzene-1, 3-diol and 2-naphthol respectively. The solvent effect of all the antipyrinylazo analogues with ethanol presented in Figure 3.

The molecular ion peaks observed for all the synthesized molecules by LC-MS strongly reveals their predicted molecular formula. The LC-MS image of $\mathbf{4 d}$ is illustrated in Figue 4.

\section{Antimicrobial Screening}

Though all the compounds showed satisfactory antimicrobial activity but the antipyrinylazo conjugated 4-hydroxycoumarin (4a) showed excellent antimicrobial activity against both gram positive and gram negative bacterial strains such as $S$. flexneri, K. pneumonia, M. luteus, S. mitis, B. subtilis and $S$. aureus in comparison to standard drug ampicillin may be due to the attachment of 4-antiprinyl moiety at C-3 position of 4-hydroxycoumarin. However, the compounds $4 \mathrm{~b}, 4 \mathrm{~d}$ and $4 \mathrm{e}$ showed moderate activity (Table 2).

\section{Acute Toxicity}

The acute oral toxicity study revealed that there was no mortality found to be observed in the experimented animals and the synthesized antipyrinylazo analogues are found to be safe up to $2000 \mathrm{mg} / \mathrm{kg}$ body weight.

\section{CONCLUSION}

The entire novel synthesized 4-aminoantipyrin conjugated azo molecules with different nucleophilic substrates are structurally found to be confirmed by FT/IR and ${ }^{1} \mathrm{H}$ NMR spectral analysis. The antimicrobial ability of the synthesized molecules was evaluated by measuring the zone of inhibition that produced when the test molecule is applied against the microorganisms. Though the

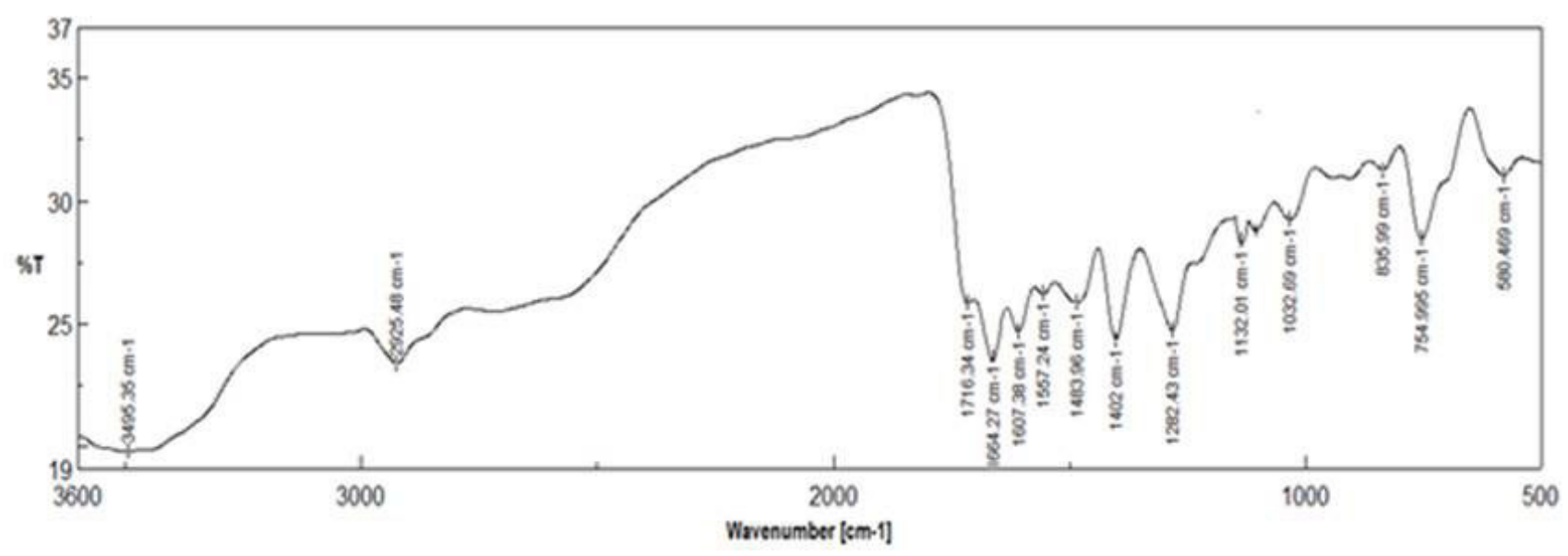

Figure 1: FT/IR of 4-[(4-Hydroxy-2-Oxo-2h-Chromen-3-YI) Diazenyl]-1, 5-Dimethyl-2-Phenyl-1h-Pyrazol-3(2h)-One (4a). 


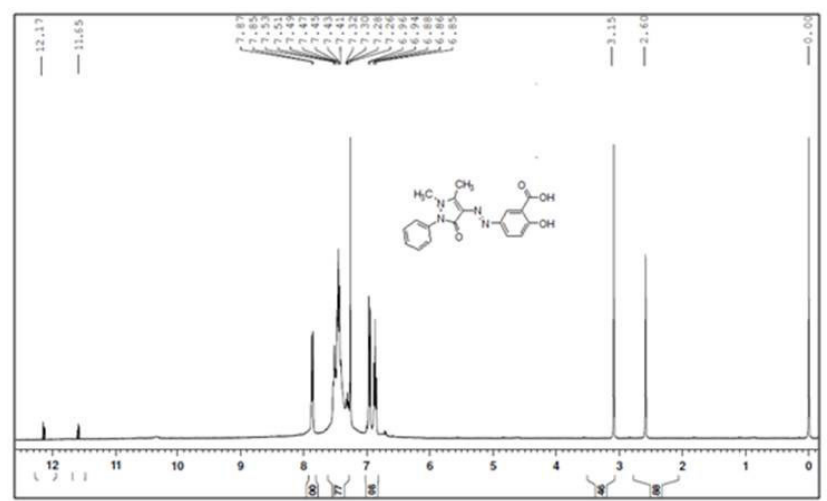

Figure 2: ${ }^{1} \mathrm{H}$ NMR of 5-((1, 5-dimethyl-3-oxo-2-phenyl-2,3-dihydro-1H-pyrazol-4-yl) diazenyl)-2-hydroxy benzoic acid (4c).

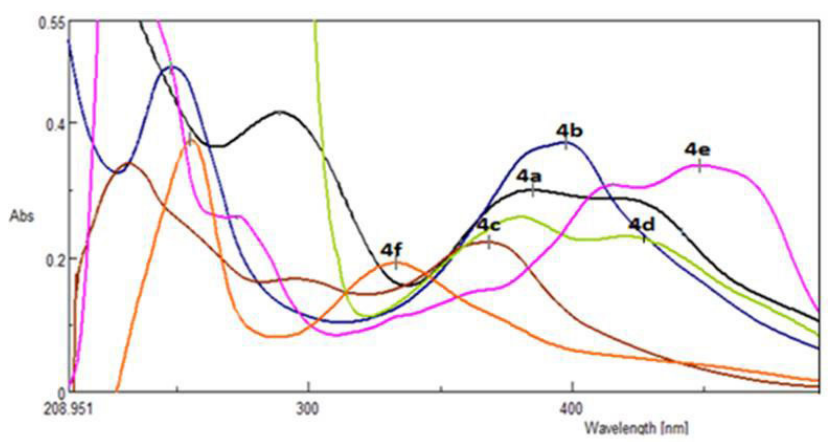

Figure 3: The solvatochromic effect showing by the antipyrinylazo azo molecules (4a-4f) with ethanol

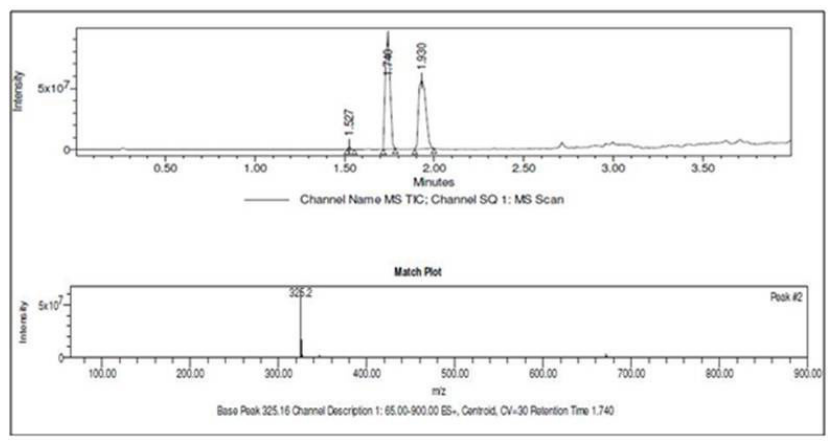

Figure 4: LC-MS of 4-((2, 4-dihydroxyphenyl) diazenyl)-1, 5-dimethyl-2-phenyl-1H-pyrazol-3(2H)-one (4d).

synthesized molecules showed satisfactory antimicrobial activity but the compound $\mathbf{4 a}$ showed significant antimicrobial activity against a wide range of bacterial strains than other molecules in comparison to standard ampicillin. Thus the antipyrinylazo analogue $4 \mathrm{a}$ may be recommended as a lead in the research for novel therapeutic agent for the treatment of antimicrobial infections.

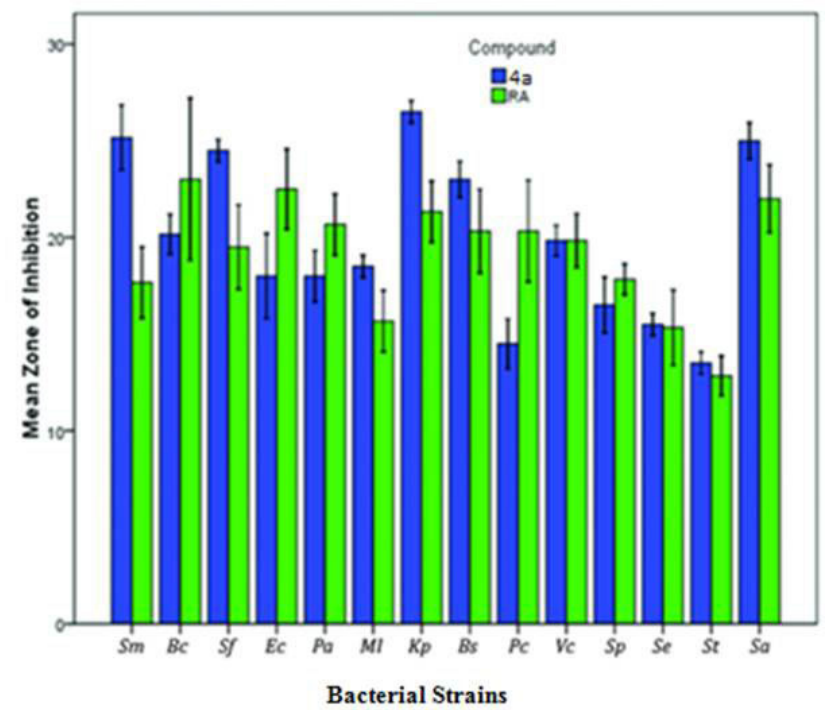

Ec-Escherichia coli, Se-Salmonella enterica ser:typhi, St-Salmonella enterica typhimurium, Sp-Salmonella enterica paratyphi, Sf-Shigella flexneri, Pa-Pseudomonas aeruginosa, Vc-Vibrio cholera, Kp-Klebsiella pneumonia, Ml- Micrococcus luteus, Bc-Bacillus circulans, Sm-Streptococcus mitis, Pc-Pectobacterium carotovorum, Bs- stain hswx88- Bacillus subtilis, Sa - Staphylococcus aureus, RA-Reference Antibiotic (ampicillin)

Figure 5 : Graphical presentation of antimicrobial activity of 4-[(4-hydroxy-2-oxo-2H-chromen-3-yl) diazenyl]-1, 5-dimethyl2-phenyl-1H-pyrazol-3(2H)-one (4a).

Table 1: UV-Visible spectral data $\left(\lambda_{\max } ; \mathrm{nm}\right)$ of the antipyrinylazo molecules using different solvents

\begin{tabular}{|c|c|c|c|c|c|}
\hline \multirow{2}{*}{ Comps. } & $\boldsymbol{\lambda}$ max & $\lambda$ max & $\boldsymbol{\lambda}$ max & $\boldsymbol{\lambda} \max$ & $\boldsymbol{\lambda} \max$ \\
\cline { 2 - 6 } & Methanol & Ethanol & DMF & DMSO & THF \\
\hline 4a & 389 & 385 & - & - & 475 \\
\hline 4b & 294 & 397 & 409 & 410 & 405 \\
\hline 4c & 383 & 368 & 381 & 383 & 441 \\
\hline 4d & 380 & 420 & 425 & 428 & 413 \\
\hline 4e & 460 & 448 & - & 461 & 454 \\
\hline 4f & 348 & 347 & 480 & 357 & - \\
\hline
\end{tabular}

\section{ACKNOWLEDGEMENT}

The authors are indebtly acknowledge to the Dean, School of Pharmaceutical Sciences, Siksha 'O' Anusandhan University, Director of NISER, IMMT, and Dr. Bijaya Bhusan Nanda, Deputy Director Regional Institute of Planning, Applied Economics and Statistics, Bhubaneswar, India. The Chairman and Principal of Sri Jayadev College of Pharmaceutical Sciences, Bhubaneswar is also acknowledged for their constant inspiration to pursue this research. 


\begin{tabular}{|c|c|c|c|c|c|c|c|}
\hline 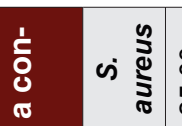 & 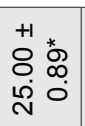 & 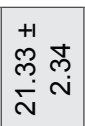 & ' & $\begin{array}{l}\underset{N}{+1} \\
\stackrel{+}{\sim}\end{array}$ & 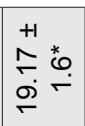 & & $\begin{array}{l}\hat{0} \\
\dot{0} \\
\stackrel{+}{1}\end{array}$ \\
\hline 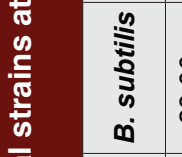 & 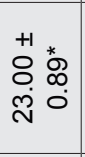 & $\begin{array}{ll}+1 & * \\
\infty & * \\
\infty & \infty \\
\infty & \stackrel{-}{-} \\
\stackrel{-}{-}\end{array}$ & $\begin{array}{l}+1 \\
\stackrel{n}{m} \\
\stackrel{m}{\circ} \\
\stackrel{0}{\circ}\end{array}$ & 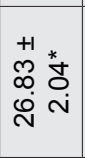 & 1 & ' & ָָ \\
\hline 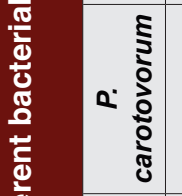 & 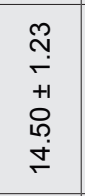 & 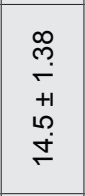 & ' & ' & ' & 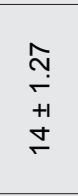 & 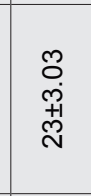 \\
\hline $\begin{array}{l}\text { है } \\
\text { है } \\
\text { जो }\end{array}$ & 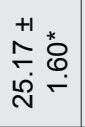 & $\begin{array}{l}+1 \\
\stackrel{*}{*} \\
\hat{0}: \stackrel{0}{0} \\
\stackrel{\sim}{*}\end{array}$ & 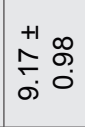 & ' & 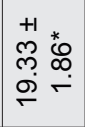 & ' & 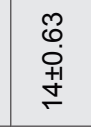 \\
\hline 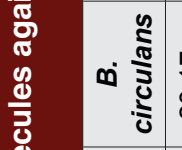 & $\begin{array}{ll}+1 & \infty \\
& \infty \\
\check{c} & 0 \\
& 0\end{array}$ & 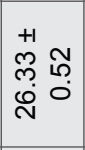 & ' & 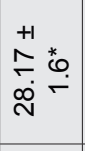 & $\begin{array}{l}+1 \\
\stackrel{+1}{*} \\
0 \\
\stackrel{0}{\sim} \\
\stackrel{0}{0}\end{array}$ & ' & 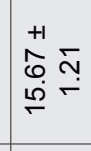 \\
\hline 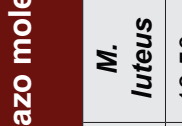 & 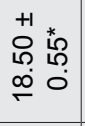 & 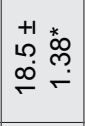 & $\begin{array}{lll}+1 & + \\
L & \infty & 0 \\
\infty & \infty & 0\end{array}$ & ' & $\stackrel{+1}{\rightleftharpoons} \underset{\leftarrow}{\leftarrow}$ & 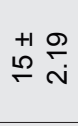 & 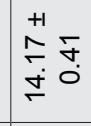 \\
\hline 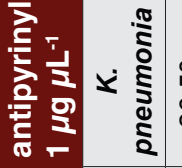 & 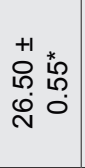 & $\begin{array}{l}0 \\
0 \\
+1 \\
\infty \\
\infty\end{array}$ & $\begin{array}{l}\text { on } \\
0 \\
0 \\
0 \\
+1 \\
\infty \\
\infty\end{array}$ & $\begin{array}{l}+1 \\
\dddot{\infty} \\
\infty \\
\stackrel{+}{\circ} \\
\stackrel{\circ}{\leftarrow}\end{array}$ & $\begin{array}{l}\stackrel{g}{\check{C}} \\
+1 \\
\stackrel{+}{\leftarrow}\end{array}$ & ' & 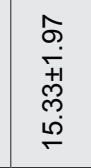 \\
\hline 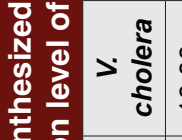 & 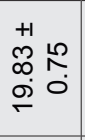 & $\begin{array}{l}\stackrel{*}{*} \\
+1 \\
\infty \\
\sim\end{array}$ & ' & ' & ' & 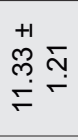 & $\begin{array}{c}1 \\
11\end{array}$ \\
\hline 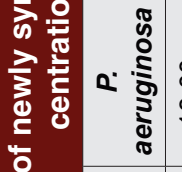 & 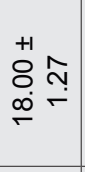 & $\begin{array}{l}\stackrel{*}{\leftarrow} \\
\dot{+} \\
+1 \\
\stackrel{N}{N}\end{array}$ & ' & 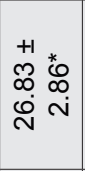 & 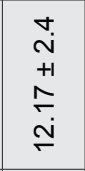 & $\begin{array}{l}0 \\
0 \\
+1 \\
+1 \\
+\end{array}$ & İ \\
\hline 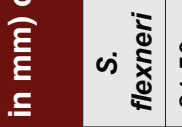 & 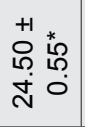 & $\begin{array}{l}+1 \\
\infty \\
\infty \\
\infty \\
\infty \\
\infty \\
\stackrel{\sim}{-}\end{array}$ & ' & 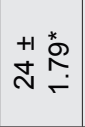 & 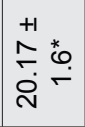 & & $\begin{array}{l}+1 \\
\stackrel{+1}{\rightleftharpoons} \\
\end{array}$ \\
\hline cis & 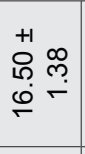 & $\begin{array}{l}\mathscr{8} \\
0 \\
0 \\
+1 \\
+\end{array}$ & ' & ' & ' & ' & $\begin{array}{l}\dot{v} \\
+1 \\
+ \\
+\end{array}$ \\
\hline c) & 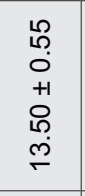 & $\begin{array}{l}\tilde{N} \\
\stackrel{+}{+} \\
+1 \\
\hat{\sigma} \\
\infty \\
\infty\end{array}$ & ' & ' & $\begin{array}{l}\text { No } \\
0 \\
+1 \\
0 \\
0 \\
0 \\
0\end{array}$ & $\begin{array}{l}\stackrel{*}{\infty} \\
\stackrel{N}{N} \\
+1 \\
0 \\
\stackrel{0}{0}\end{array}$ & 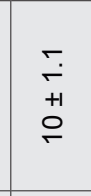 \\
\hline 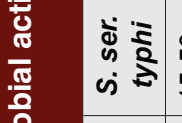 & 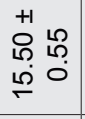 & 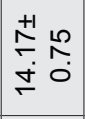 & ' & ' & $\begin{array}{ll}+1 & + \\
0 & 0 \\
0 & 0 \\
0 & 0\end{array}$ & ' & $\begin{array}{l}+1+\mathscr{g} \\
\stackrel{8}{0} \\
\stackrel{0}{0}\end{array}$ \\
\hline \begin{tabular}{c|c}
$\bar{u}$ \\
u
\end{tabular} & 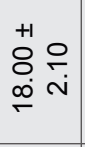 & 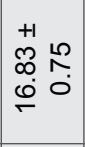 & ' & 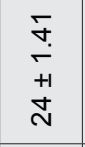 & $\begin{array}{l}\stackrel{+}{\leftarrow} \\
+1 \\
\stackrel{0}{\circ}\end{array}$ & ' & 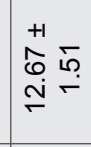 \\
\hline $\begin{array}{l}\dot{\phi} \\
\stackrel{0}{E} \\
\dot{0}\end{array}$ & \& & $f$ & q & ర্ & $\stackrel{\&}{+}$ & 4 & 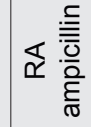 \\
\hline
\end{tabular}

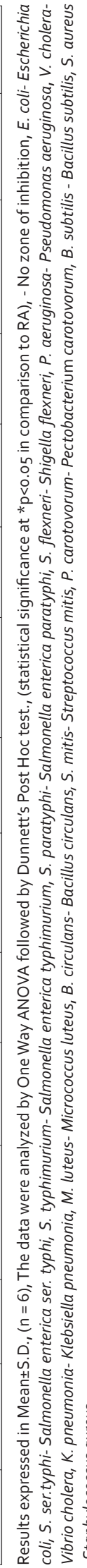

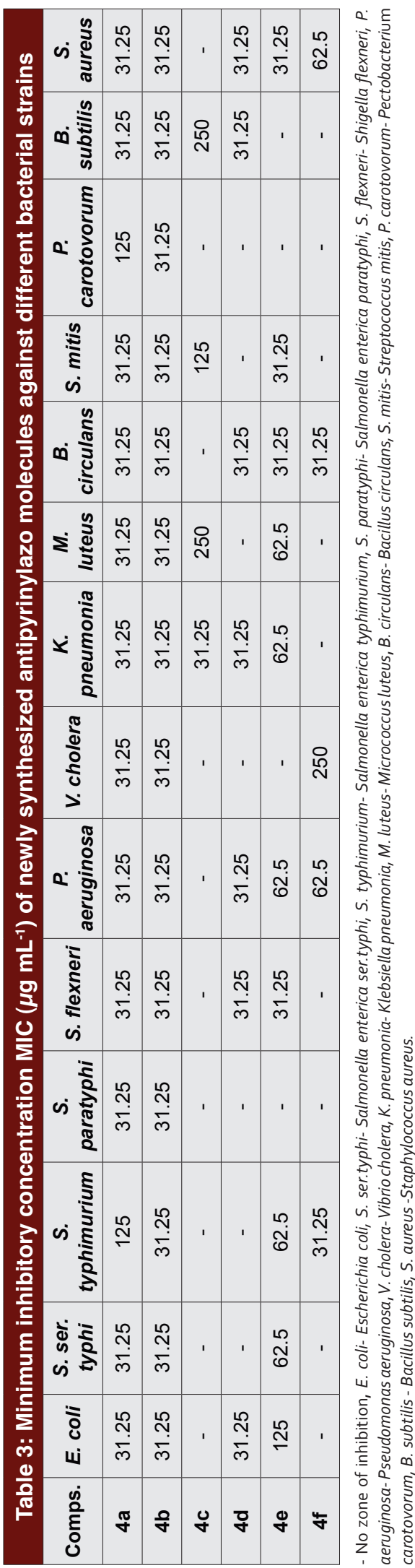




\section{CONFLICT OF INTEREST}

The authors have no conflict of interest.

\section{ABBREVIATION USED}

FT/IR: Fourier transform infrared spectroscopy; UVVis: Ultra violet visible spectroscopy; NMR: Nuclear magnetic resonance spectroscopy; LC-MS: Liqid chromatography and mass spectrometry; TLC: Thin layer chromatography; MIC: Minimum inhibitory concentration; MTCC: Microbial type culture collection; Institutional Animal Ethical Committee (IAEC); IMTECH: Institute of microbial technology; CFU: Colony forming unit; OECD: Organization for economic co-operation and development; DMSO: Dimethyl sulphoxide; RA: Reference antibiotic.

\section{REFERENCES}

1. Mariappan BP, Saha BP, Sutharson L, Haldar A. Synthesis and bioactive evaluation of pyrazolone derivatives. Ind J Chem. 2010;49B:1671-4.

2. Bondock $S$, Rabie R, Etman HA, Fadda AA. Synthesis and antimicrobial activity of some new heterocycles incorporating antipyrine moiety. European journal of medicinal chemistry. 2008;43(10):2122-9.

3. Abdel-Aziz M, Abuo-Rahma GE, Hassan AA. Synthesis of novel pyrazole derivatives and evaluation of their antidepressant and anticonvulsant activities. European journal of medicinal chemistry. 2009;44(9):3480-7.

4. Lv PC, Li HQ, Sun J, Zhou Y, Zhu HL. Synthesis and biological evaluation of pyrazole derivatives containing thiourea skeleton as anticancer agents. Bioorganic \& medicinal chemistry. 2010;18(13):4606-14.

5. Redha Al-Bayati IH, Ammar Kubba AR, Mahdi Radi H. Synthesis of new pyrazole derivatives derived from 4-hydroxy coumarin and evaluation of their biological activity. Al- Mustansiriyah J Sc. 2012;23:83-92.

6. Stefanou V, Matiadis D, Melagraki G, Afantitis A, Athanasellis G, et al. Functionalized 4-hydroxy coumarins: novel synthesis, crystal structure and DFT calculations. Molecules. 2011;16(1):384-402.
7. Velasco-Velázquez MA, Agramonte-Hevia J, Barrera D, Jiménez-Orozco A, Garcia-Mondragón MJ, et al. 4-Hydroxycoumarin disorganizes the actin cytoskeleton in B16-F10 melanoma cells but not in B82 fibroblasts, decreasing their adhesion to extracellular matrix proteins and motility. Cancer letters. 2003;198(2):179-86.

8. Prachayasittikul V, Prachayasittikul S, Ruchirawat S, Prachayasittikul V. 8-Hydroxyquinolines: a review of their metal chelating properties and medicinal applications. Drug design, development and therapy. 2013;7:1157.

9. Al-Dabbas MM, Suganuma T, Kitahara K, Hou DX, Fujii M. Cytotoxic, antioxidant and antibacterial activities of Varthemia iphionoides Boiss. extracts. Journal of ethnopharmacology. 2006;108(2):287-93.

10. Djurendic E, Vujaskovic SD, Sakac M, Ajdukovic J, Gakovic A, et al. Synthesis and biological evaluation of some new 2-oxazoline and salicylic acid derivatives. ARKIVOC. 2011; ii: 83-102.

11. Pandya JH, Jadeja RN, Ganatra KJ. Spectral characterization and biological evaluation of Schiff bases and their mixed ligand metal complexes derived from 4, 6-diacetylresorcinol. Journal of Saudi Chemical Society. 2014;18(3):190-9.

12. Hamid HM, Zeinab NM, Istabraq MA. 'Synthesis and Studies the Biological Activity of New Azo Compounds. Journal of Kerbala University. 2011;9(3):75-83.

13. Keerthi Kumar CT, Keshavayya J, Rajesh TN, Peethambar SK, Shoukat Ali AR. Synthesis, characterization, and biological activity of 5-phenyl-1, 3, 4-thiadiazole-2-amine incorporated azo dye derivatives. Organic Chemistry International. 2013.

14. Sava G, Giraldi T, Baldini L. Antitumor activity of N-diazoacetyl derivatives of glycine and phenylalanine against P388 leukemia and B16 melanoma in mice. Cancer treatment reports. 1982;66(1):179-81.

15. Browning $\mathrm{CH}$, Cohen JB, Ellingworth $\mathrm{S}$, Gulbransen R. The antiseptic properties of the amino derivatives of styryl and anil quinoline. Proceedings of the Royal Society of London. Series B, Containing Papers of a Biological Character. 1926;100(703):293-325.

16. Yazdanbakhsh MR, Ghanadzadeh A, Moradi E. Synthesis of some new azo dyes derived from 4-hydroxy coumarin and spectrometric determination of their acidic dissociation constants. Journal of Molecular Liquids. 2007;136(1):165-8.

17. Andrews M. Determination of minimum inhibitory concentrations. J Antimicrob Chemother. 2001;48(suppl 1):5-16.

18. Shridhar AH, Keshavayya J, Peethambar SK, Joy Hoskeri H. Synthesis and biological activities of bis alkyl 1, 3, 4-oxadiazole incorporated azo dye derivatives. Arab J Chem. 2012.

19. Khabnadideh S, Rezaei Z, Ghasemi Y, Montazeri-Najafabady N. Antibacterial activity of some new azole compounds. Anti-Infective Agents. 2012;10(1):26-33.

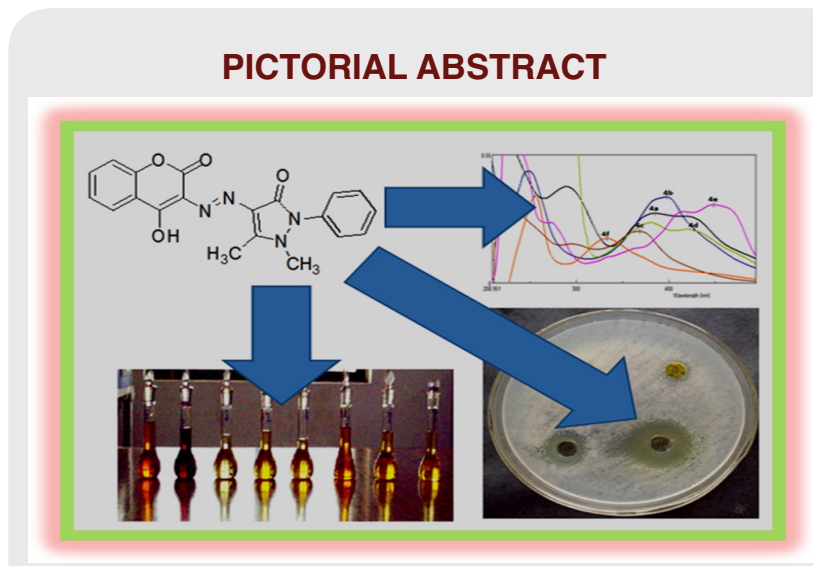

\section{SUMMARY}

- A new series of antipyrinylazo analogues are synthesized from by coupling of diazonium salts of 4-amino antipyrin with different nucleophiles.

- The novel synthesized molecules are characterized to confirm their structural environment.

- The in vitro antimicrobial activity of the synthesized molecules is investigated against 14 different gram positive and gram negative microbial strains of and results are statistically interpreted.

- The molecule 4-[/4-Hydroxy-2-oxo-2H-chromen3-yl)diazenyll-1, 5-dimethyl-2-phenyl-1H-pyrazol$3(2 H)$-one (4a) showed significant antimicrobial activity in comparison to standard (ampicillin) against $S$. flexneri, K. pneumonia, M. luteus, mitis, $B$. subtilis and $S$. aureus. 


\section{About Authors}

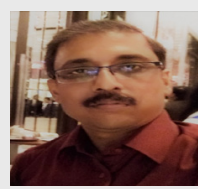

Dr.Jyotirmaya Sahoo, M.Pharm, Ph.Dis presently working as AssistantProfessor in Department of Pharmaceutics, Sri Jayadev College of Pharmaceutical Sciences, Bhubaneswar, Odisha, India. Dr. Sahoo keeps interest in research as well as academics. His research works are published in various journals of national and international repute. As a life member of Association of Pharmaceutical Teachers of India, Indian Pharmaceutical Association, Indian Hospital Pharmacists Association, Orissa Chemical Society and Inpharm Association he remains well involved in all the activities conducted by the respective body.

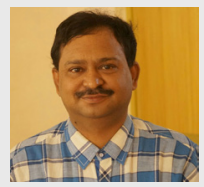

Dr. Sudhir Kumar Paidesetty, M. Pharm, Ph. D is working as Associate Professor, Faculty of Pharmacy, School of Pharmaceutical Sciences, Siksha 'O' Anusandhan University, Bhubaneswar, and Odisha, India. He has kept his research interest in in silico investigation and biological evaluation of novel synthesized heterocyclic molecules. Under his supervision a good number students are pursuing their Ph. D. and also awarded with Ph.D. He has published a number of publications in different reputed journals and books in national and international repute.

Cite this article: Jyotirmaya S, Kumar PS. A Study on Antimicrobial Evaluation of Newly Synthesized Antipyrin Analogues. Indian J of Pharmaceutical Education and Research. 2017;51(4):740-7. 